\title{
Graphene Augmented Nanofibers and their Versatile Applications
}

\author{
Irina Hussainova ${ }^{1,2}$ and Roman Ivanov ${ }^{1}$ \\ ${ }^{1}$ Tallinn University of Technology, Ehitajate 5, 19180 Tallinn, Estonia \\ ${ }_{2}^{2}$ ITMO University, Kronverksky 49, St. Petersburg, 197101, Russian Federation
}

Received: June 25, 2020

\begin{abstract}
Both business and research communities provide considerable funding in development of novel materials added by graphene or graphene-like structures as well as devices based on these materials as graphene offers the unique properties, which can be exploited in nowadays industry. In this review, the different applications of tailored hybrid structures of nanofibers covered by multi-layered defective graphene are demonstrated alongside with the bottom-up approach to fabricate such kind of structures. The main attention is paid onto nanostructural modifications of carbon layers encapsulating alumina nanofibers to ensure wide possible applications of the designed nanostructures. The materials has shown potential uses as reinforcements for multifunctional electro-conductive ceramics, electrochemical conversion, highly sensitive sensing, and as substrates for bioapplications. The general synthetic rules towards graphene deposition and the guidance and inspiration on the trends for the specific choice of structures towards applications of interest are demonstrated in this paper.
\end{abstract}

\section{INTRODUCTION}

The explosive interest in two-dimensional sheets of $\mathrm{sp}^{2}$ - hybridized carbon stems from extraordinary mechanical, structural, thermal, electrical, and electronic properties, and, therefore, from a potential it may provide for future advanced and even unexpected commercial applications [1,2]. A single-layer graphene or "real" graphene represents twodimensional sheet of well-arranged carbon atoms with outstanding charge carrier mobility (electron mobility is estimated to be up to $15000 \mathrm{~cm}^{2} \mathrm{~V}^{-1} \mathrm{~s}^{-1}$ [3]) and exceptional stiffness (modulus of elasticity is predicted to be up to $1.0 \mathrm{TPa}$ [4]). Recently, graphene was proved as a bio-compatible material that may be successfully used for bio engineering and sensors [5].

However, because an up-scalable production of a defect-free single-layer graphene is a great challenge up to now, the multi-layered graphene, consisting of several graphene layers, and/or highly defected graphene-like sheets are widely used. Properties of few-layered stacks of graphene-like sheets are distinguishing from properties of an "ideal" graphene. For example, an assembly becomes increasingly metallic showing excellent possibility for functionalization and/or decoration with nanoparticles required for the specific application. Utilization of carbon nanostructures for a wide variety of applications requires a procedure for preparation of different objects depending on their specific needs.

Among recent key developments, the bottomup synthesis routes [6] have the potential for production of carbon nanostructures at an affordable cost. One of the well-developed approaches is a thermal decomposition of silicon on the surface of $6 \mathrm{H}-\mathrm{SiC}$ [7]. A synthesis route using chemical vapor deposition (CVD) has found a wide application as being the prospective one due its possibility to produce defect-free graphene of a large size [8]. 
Method of the direct CVD growth of multilayered graphene-like structures on insulating substrates represents the further challenge for research community. A recently developed method for the direct CVD of a single- or a few-layer graphene film onto the dielectric surfaces via a controlled metal evaporation from the covering metal foil during the catalytic growth [9], although presented an interesting approach, requires a high quality sacrificial copper layer and precisely controllable parameters of the process. The comparative analysis of different methods is given in Table 1.

The 3D architecture of nanostructures is currently represented by activated carbons, graphenated-CNTs $[10,11]$, graphene nanoplatelets [12] with a high density of the exposed graphene edges, etc. The reliable procedure to produce $3 \mathrm{D}$ foliated fuzzy graphene-like structures and control over their properties is of the primary importance for progress in carbon-related areas, which may enable a range of materials features starting with the optimized energy/power densities, durability, and ending by the potentially reducing cost and minimal environmental impact. New product should be commercially viable and substantially surpass the performance of the existing materials at comparable manufacturing costs.

As the fundamental advantage of a graphenated nanostructure is the electroconductivity combined with a tailorable surface area, a framework of the hybrid nanofibers coupled with the specified density of the graphene edges may serve many different tasks and find wide applications in industry. Development of graphene of various morphologies is one of the main tasks of the present review, which summarizes possible applications of graphene-like nanostructures deposited onto insulating inorganic substrates.

\section{EXPERIMENTAL}

\subsection{Materials and experimental set-up}

To produce different morphologies of the graphenelike nanostructures, a network of ceramic nanofibers, manufactured by a recently developed process of controlled liquid phase oxidation of an aluminium melt, was chosen as a substrate for carbon deposition. The network represents a mesoporous complex structure consisting of highly-aligned self-assembled oxide nanofibers with a single nanofiber diameter ranged from 5 up to $50 \mathrm{~nm}$ and a narrow distribution of nanofibers diameters throughout one block. The typical aspect ratio is $10^{7}$, Fig. 1, and the specific surface area measured by BET method is ranged from 142 up to $175 \mathrm{~m}^{2} \mathrm{~g}^{-1}$ depending on fibers diameter. The as-produced fibers mostly composed of partially hydrated (2-6 wt.\%) gamma-alumina phase that can be converted into alfa-alumina by a heat treatment

Table 1. Methods of graphene fabrication and possible applications of the graphene produced.

\begin{tabular}{lllll}
\hline Method & $\begin{array}{l}\text { Crystallite } \\
\text { size }\end{array}$ & Sample size & $\begin{array}{l}\text { Charge carrier } \\
\text { mobility } \\
\text { (at ambient } \\
\text { temperature }) \\
{\left[\mathrm{cm}^{2} \mathrm{~V}^{-1} \mathrm{~s}^{-1}\right]}\end{array}$ & Applications \\
\hline $\begin{array}{l}\text { Mechanical } \\
\text { exfoliation }\end{array}$ & $>1000$ & $>1$ & $\begin{array}{l}>2 \times 10^{5} \text { and } \\
>10^{6}(\text { at low } \\
\text { temperature) }\end{array}$ & Research \\
\hline $\begin{array}{l}\text { Chemical } \\
\text { exfoliation }\end{array}$ & $<0.1$ & $\begin{array}{l}\text { Infinite as } \\
\text { a layer of } \\
\text { overlapping } \\
\text { flakes }\end{array}$ & $\begin{array}{l}100 \text { (for a layer of } \\
\text { overlapping flakes) }\end{array}$ & $\begin{array}{l}\text { Coatings, paint/ink, composites, } \\
\text { transparent conductive layers, } \\
\text { energy storage, bioapplications }\end{array}$ \\
\hline $\begin{array}{l}\text { Chemical } \\
\text { exfoliation via } \\
\text { graphene oxide }\end{array}$ & $\sim 100$ & $\begin{array}{l}\text { Infinite as } \\
\text { a layer of } \\
\text { overlapping } \\
\text { flakes }\end{array}$ & $\begin{array}{l}100 \text { (for a layer of } \\
\text { overlapping flakes) }\end{array}$ & $\begin{array}{l}\text { Coatings, paint/ink, composites, } \\
\text { transparent conductive layers, } \\
\text { energy storage, bioapplications }\end{array}$ \\
\hline CVD & 1000 & $\sim 1000$ & 10000 & $\begin{array}{l}\text { Photonics, nanoelectronics, } \\
\text { transparent conductive layers, } \\
\text { sensors, bioapplications }\end{array}$ \\
\hline SiC & & & $\begin{array}{l}\text { High-frequency transistors and } \\
\text { other electronic devices }\end{array}$ \\
\hline
\end{tabular}



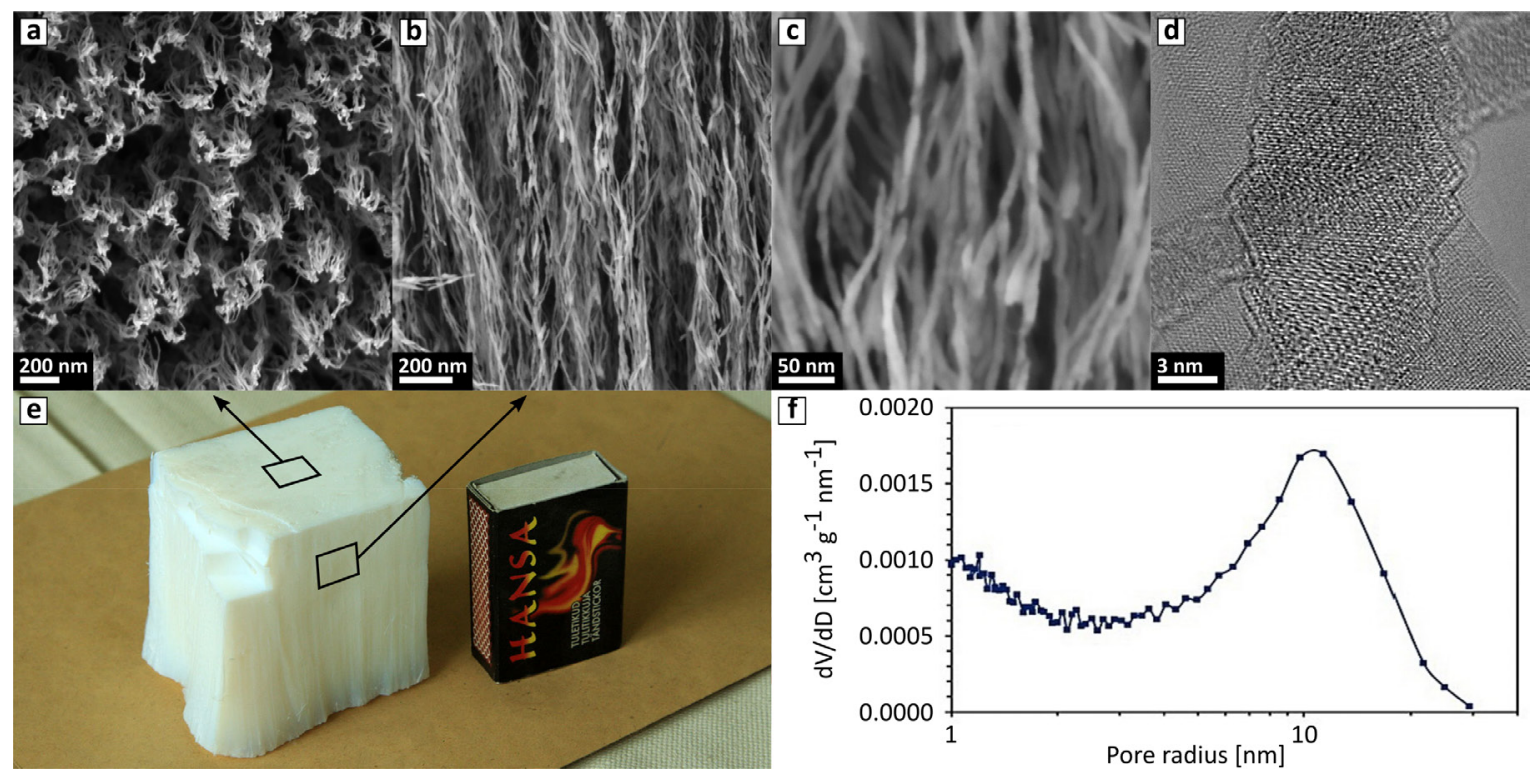

Fig. 1. SEM micrographs of top (a) and side (b, c) of the network of nanofibers. HR-TEM image of separated nanofibers (d). Optical photograph of the block of ceramic nanofibers (e). Differential pore size distribution in the network determined with the help of nitrogen adsorption (f).

at temperatures exceeded $1250{ }^{\circ} \mathrm{C}$ [13]. For carbon deposition onto the $85-95 \%$ porous substrate, a custom-made thermal "hot-wall" chemical vapour deposition setup has been worked out as detailed elsewhere [14,15].

For carbon deposition without catalyst, the network of ceramic nanofibers was directly placed into the reactor preheated up to $1000{ }^{\circ} \mathrm{C}$ in the atmosphere of methane $\left(\mathrm{CH}_{4}\right)$ flowing with a rate of $50 \mathrm{~cm}^{3} \mathrm{~min}^{-1}$ and nitrogen $\left(\mathrm{N}_{2}\right)$ flowing with a rate of $500 \mathrm{~cm}^{3} \mathrm{~min}^{-1}$ required for elimination of the products of reaction. Before deposition, each sample was first annealed for $5 \mathrm{~min}$ in air and then $5 \mathrm{~min}$ in nitrogen to purify the substrate from any impurities and/or bond water. Time of the reaction was adjusted depending on the desired structure of the coating. Graphene growth was performed by sequential introduction of the mixture of gases: methane, as a carbon precursor, and nitrogen and/or hydrogen, as a carrier gas, that allows control of the morphology of carbon layers.

\subsection{Characterization}

Weight of a deposited coating was determined by the ELTRA 84 analytical balances. Microstructural features were examined by a high-resolution scanning electron microscopy (HR-SEM) Zeiss HR Gemini FESEM Ultra 55 equipped with Bruker EDX system ESPRIT 1.8 suitable for energydispersive X-ray measurements. Morphology at a higher magnification and structure of carbon coating was studied using transmission electron microscope JEOL JEM-2200FS HR-TEM with two Cs-correctors, $200 \mathrm{kV}$ field emission gun (FEG) and in-column energy filter (Omega Filter) configured to produce a high-end energy filtered imaging. Raman spectroscopy, used for characterization of carbon layers, was performed with the help of Horiba JobinYvon HR800 high resolution Raman spectrometer equipped with a green $\mathrm{Nd}: \mathrm{YAG}$ laser $(\lambda=532.1 \mathrm{~nm})$, a red He-Ne laser $(\lambda=632.8 \mathrm{~nm})$, and a multichannel CCD detection system in the backscattering configuration. For peaks fitting and peaks parameters calculation MagicPlot software was applied. Interrelation between graphene flakes evolution and Raman peaks was examined. Five samples with gradual increase of size and density of flakes with clearly distinguishable morphological features were chosen for investigation. Raman signals were collected from five adjacent points and averaged; for isolation of a signal from the flakes, the spectrum from the sample with the weight gain of $26 \%$ was used as a baseline and extracted from all other spectra. X-ray photoelectron spectroscopy (XPS) was performed with an Omicron Multiprobe XPS system with a base pressure of $2 \times 10^{-10} \mathrm{mbar}$, using a monochromated $\mathrm{Al} \mathrm{K}$ source $(h v=1486.6 \mathrm{eV})$ and an EA125 U5 analyzer at a $45^{\circ}$ takeoff angle. Wide surveys were collected at $50 \mathrm{eV}$ pass energy, while core level spectra were collected at $20 \mathrm{eV}$ pass energy. Data collected were analyzed using CasaXPS software. The carbon content deposited onto the fibers was determined by thermogravimetric analysis using Stanton Redcroft 
device at maximum temperature of $950{ }^{\circ} \mathrm{C}$ in air. The heating rate was settled to $5{ }^{\circ} \mathrm{C} \cdot \mathrm{min}^{-1}$. Specific surface area was estimated with the help of a Quantachrome Autosorb iQ instrument running nitrogen physisorption measurements at $77 \mathrm{~K}$.

\section{GRAPHENE AUGMENTED INORGANIC NANOFIBERS (GAIN)}

\subsection{Graphene-like nanostructures}

Depending on the process parameters, the nanostructures of different morphologies can be produced as either "smooth" coatings or foliated "fuzzy" sheets as shown in Fig. 2.

As soon as the weight gain $(\Delta W)$ of the carbon coating is reached of about $\Delta \mathrm{W}=150 \%$, the formation of the graphene flakes along the longitudinal axis of the fiber is started. The appearance of foliates is similar to the leaves of aquatic plants "Leptodictyum riparium ": quite homogeneously distributed foliates grow perpendicular to the fiber surface and their density is regulated by process parameters.

Fig. 3 indicates the carbon increment registered in a set on samples grown at $1000{ }^{\circ} \mathrm{C}$ without catalyst at a different deposition time and a rate of methane flow. At the constant temperature, the most affecting factor in controlling layers morphology is the time of reaction. Extending the deposition time provides a higher weight gain, and a larger number of the layers. Fig. 4 demonstrates the sample gained $170 \%$ of the weight with the clearly recognizable 7-10 graphene layers. The maximum achieved $\Delta W$ is $869.7 \%$ produced in $\mathrm{CH}_{4}$ flow $200 \mathrm{~cm}^{3} \mathrm{~min}^{-1}$ with $120 \mathrm{~min}$ growth time. The set of experiment performed for a longer time ( 5 and 48 hours with the weight gain of $1096.2 \%$ and $1171.5 \%$, respectively) did not reveal any substantial difference in the flakes shape, distribution and density as compared with the specimen treated for $2 \mathrm{~h}$. Therefore, the saturation in carbon deposition may be explained by limited room for foliates growth that is essentially determined by the inter-fibers distance in a substrate. The saturation occurs at $\Delta W$ of around $700-900 \%$, due to difficulties for penetration of carbon atoms deep inside the sample representing a branched structure. Gas penetration or inter-fibers channels closing is fully completed at around $\Delta W=1200 \%$.

With an increase in number of layers, the size of the graphene domains increases. The boundary between domains may play a role of nucleation centres for new domains creation. The TEM study of the microstructural features revealed slight oscillation of the flakes that interferes sharpness at the edges of foliates. Fig. 5 shows the HRTEM images of the foliated graphene multi-layers indicating the structural features of the coating deposited at the flow of $\mathrm{CH}_{4}$ during 90 and $120 \mathrm{~min}$.

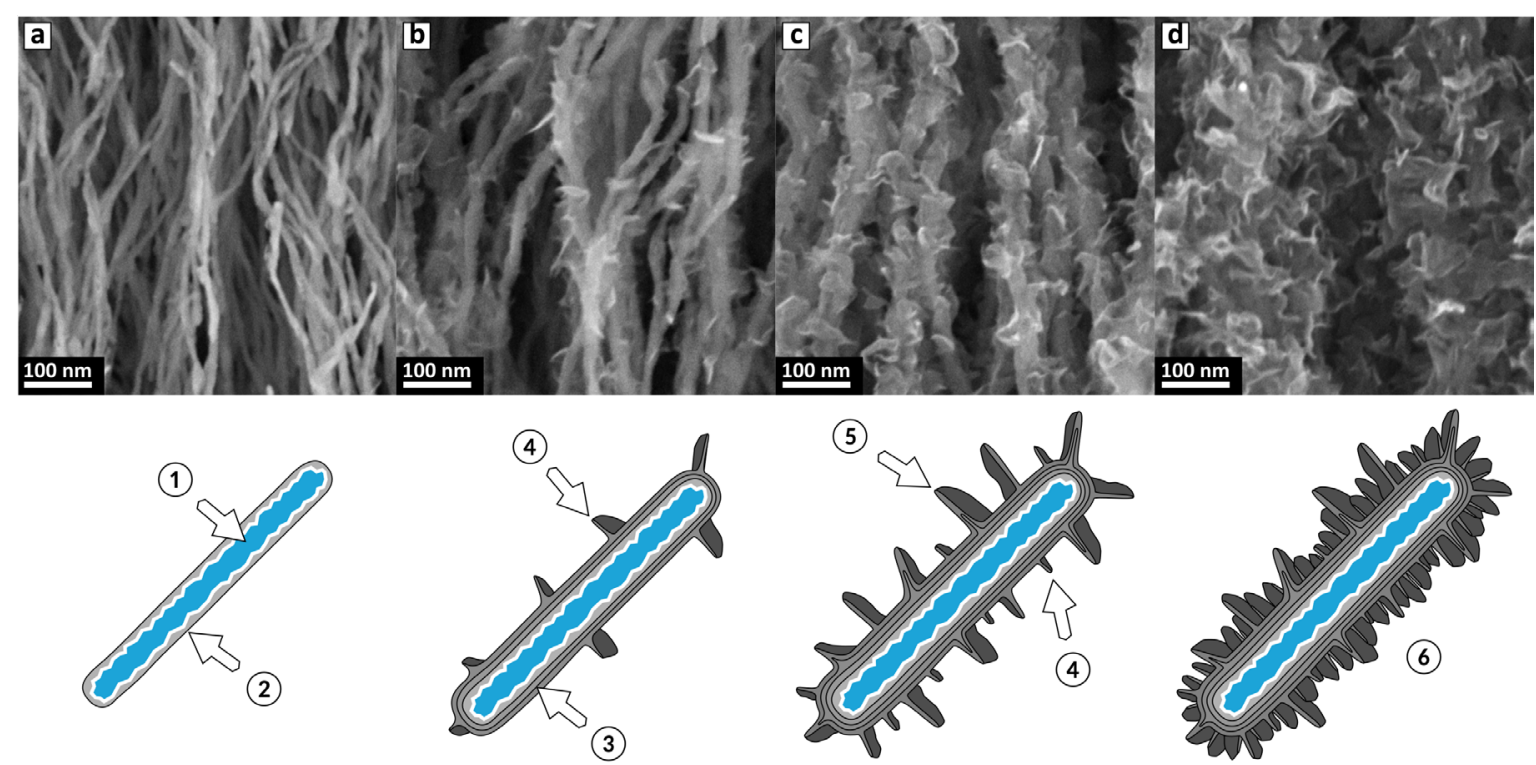

Fig. 2. SEM images of different morphologies of graphene-like structures (a-d). Schematic of the structures: Label 1 indicate substrate fiber, 2 - first few (1-5) layers, 3- many (5-15) layers, 4 - new thin flake, 5 - evolved thick flake, 6 - resulting coating with a maximum density of the flakes. 

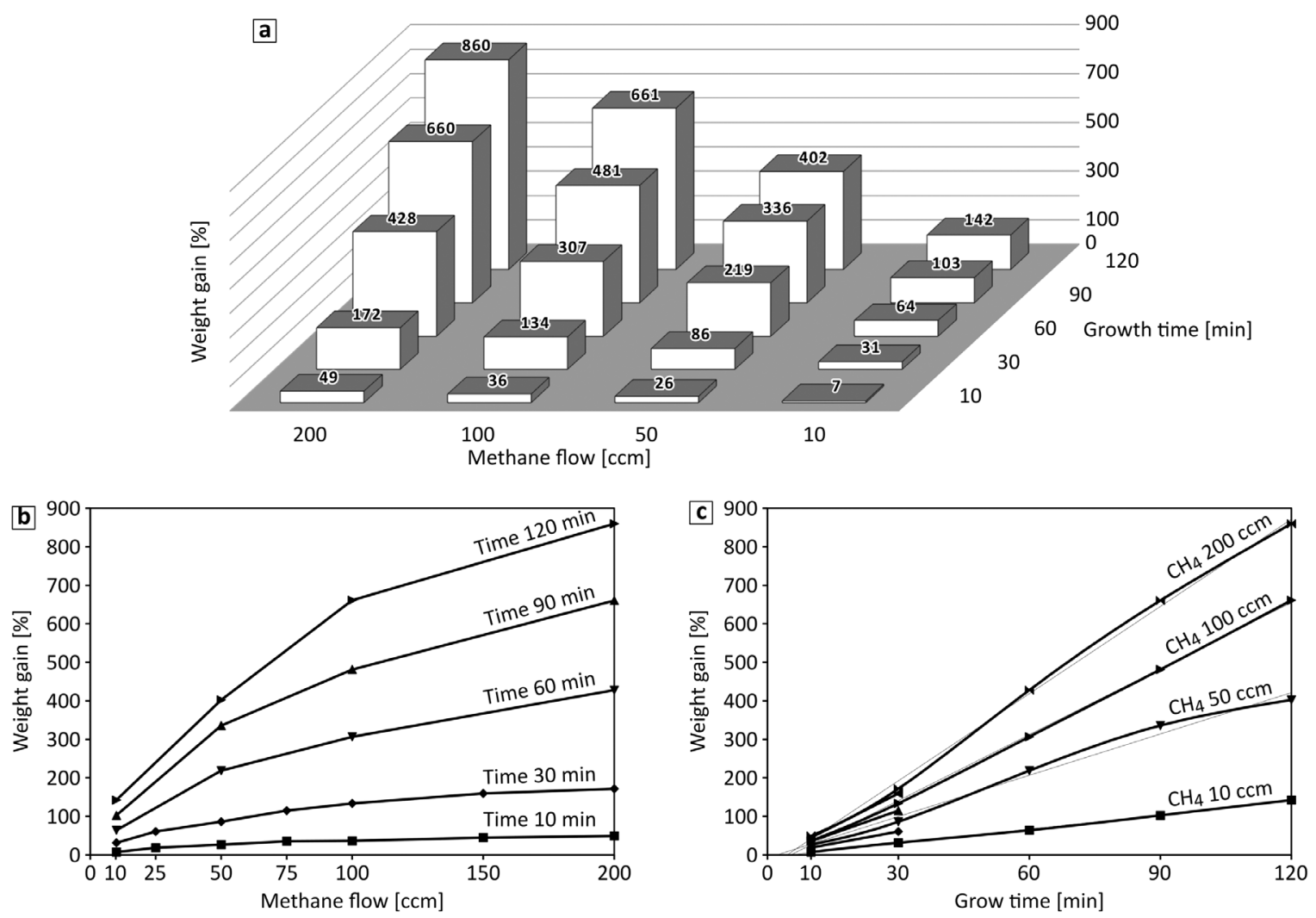

Fig. 3. Weight gain at different methane flow rates and growth time (a). Effect of methane flow rate (b) and growth time (c) on weight gain.

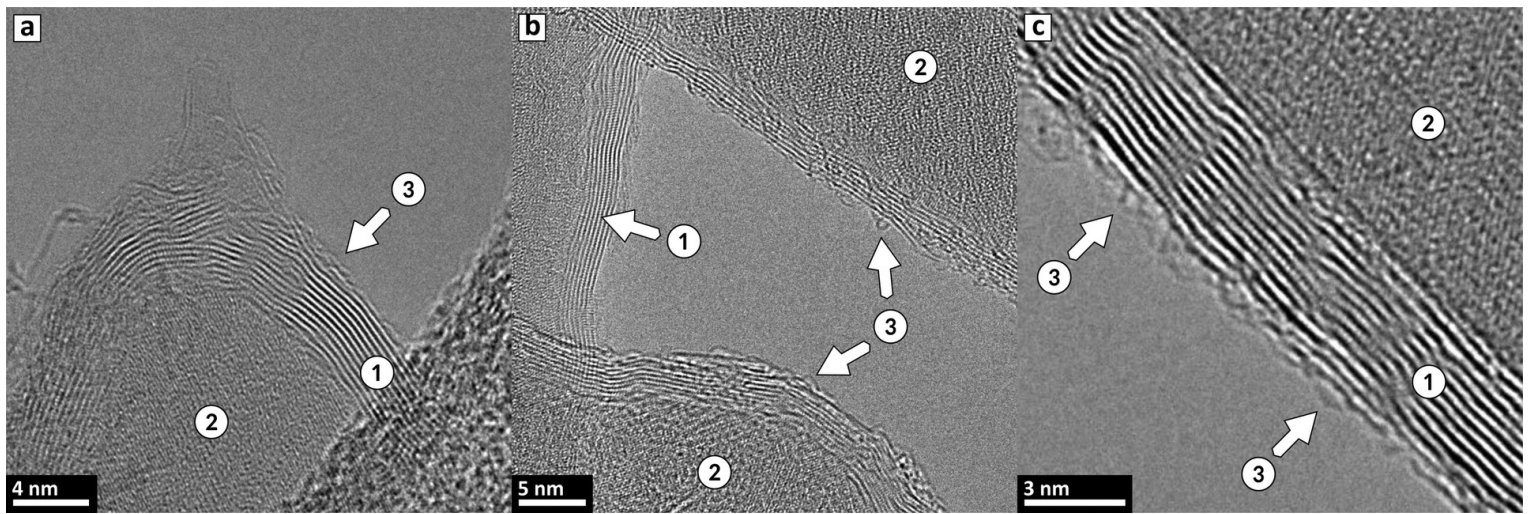

Fig. 4. TEM images of carbon coating consisting of up to 10 graphene layers (a-c). Label 1 points to stacked graphene layers, 2 marks a substrate nanofiber; and 3 shows outer highly defective layer.

Fig. 6 provides an insight into the structure of foliates. The multi-layered graphene sheets can obviously be seen giving quite a high density of free edges that can successfully be used for electrochemical and sensors applications [16-18].

Study of the mechanism of foliates formation may give a new insight into tailoring nanostructures. A stress-buckling mechanism, described elsewhere for the graphenated CNTs [19], suggested a residual stress build-up between CNT walls due to unequal growth rates. Here, an alternative method is proposed. Carbon radicals in close vicinity of the unsaturated aluminium sites and/or structural defects on the substrate surface create the nucleation seeds for the development of foliates. Then, during growing, the expanding domains touch each other to form a specific structure. The possible options can be sub-divided into two parts depending of the availability of the nucleation sites. Options for "smooth" surface with a low amount of sites (types A and B) as well as "rough" surface with considerable amount of sites (types C and D) are provided in Fig. 7.

To study the evolution of foliates, the following parameters were chosen: methane flow rate 10, 25, 

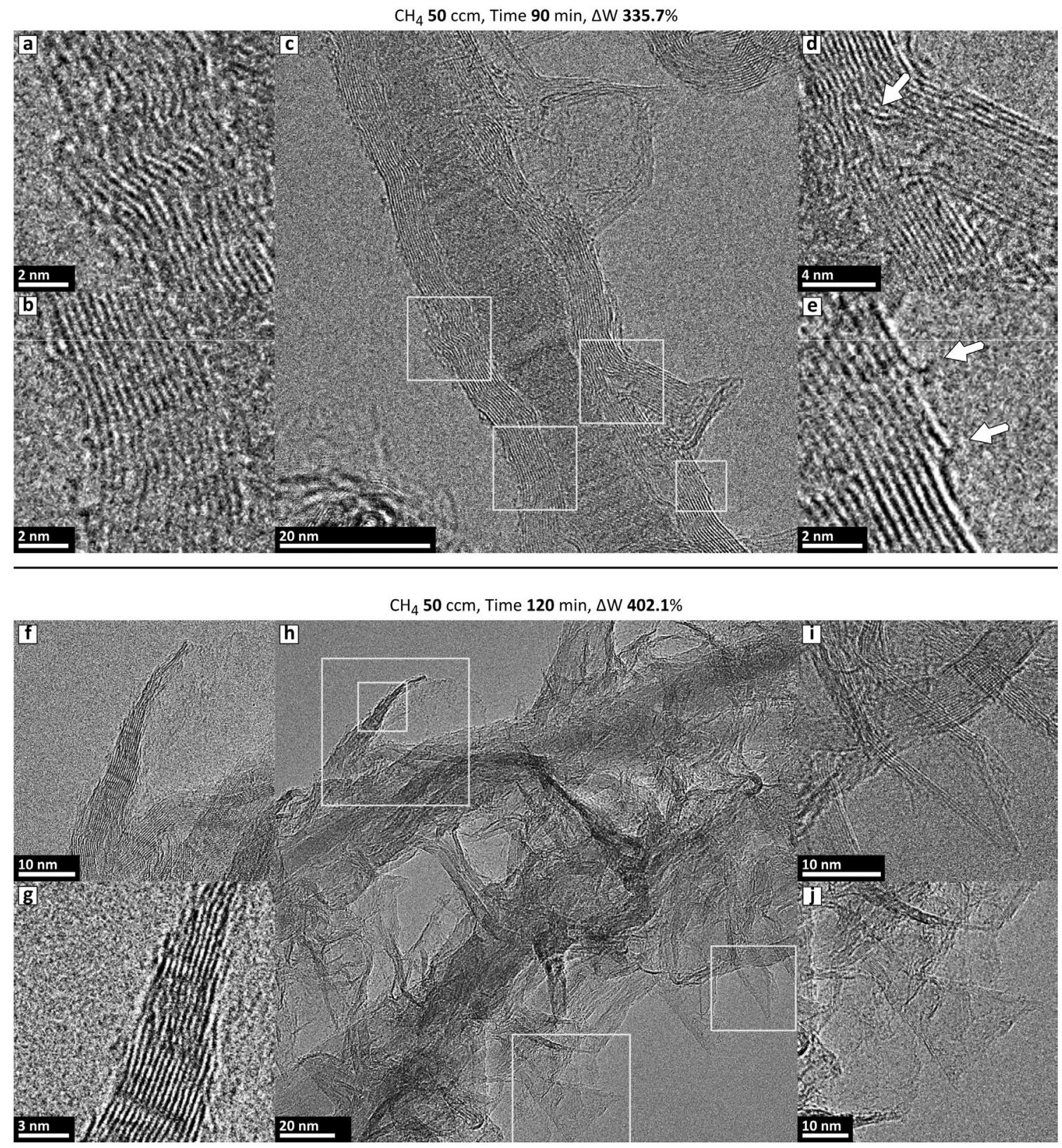

Fig. 5. TEM images of coating structure in details and graphene flakes internalorganization: (a, b) -graphene layers; (c) - general view with marks of zoomed areas; (d) - point of bifurcation of graphene layers; (e) - free edges of the outer layers; (f, g) - nanostructure of foliates; (h) - common view of the foliated structure; $(\mathrm{i}, \mathrm{j})$ - flakes of few graphene layers.

$50,75,100,150$, and $200 \mathrm{~cm}^{3} \mathrm{~min}^{-1}$ and growth time 10, 30, 60, 90, and 120 min. Fig. 8 illustrates the effect of the reaction time and the methane' flow rate on morphology of the graphene-like structures. The evolution of the graphene flakes is visually seen. First discernible flakes appear when the weight gain $\Delta W=100 \%$. In the range $\Delta W=200-400 \%$, nano-foliates fast occupy all available space increasing in size and density.
After reaching $\Delta W=500 \%$, it is hardly to find morphological difference between samples in the HR-SEM images. Therefore, to produce the samples relatively fast and with coating weight of near maximum, it is preferable to use a higher available methane flow; however, to produce the well-developed surface, the best way is to use methane flow of $50 \mathrm{~cm}^{3} \mathrm{~min}^{-1}$ or less adding hydrogen. 


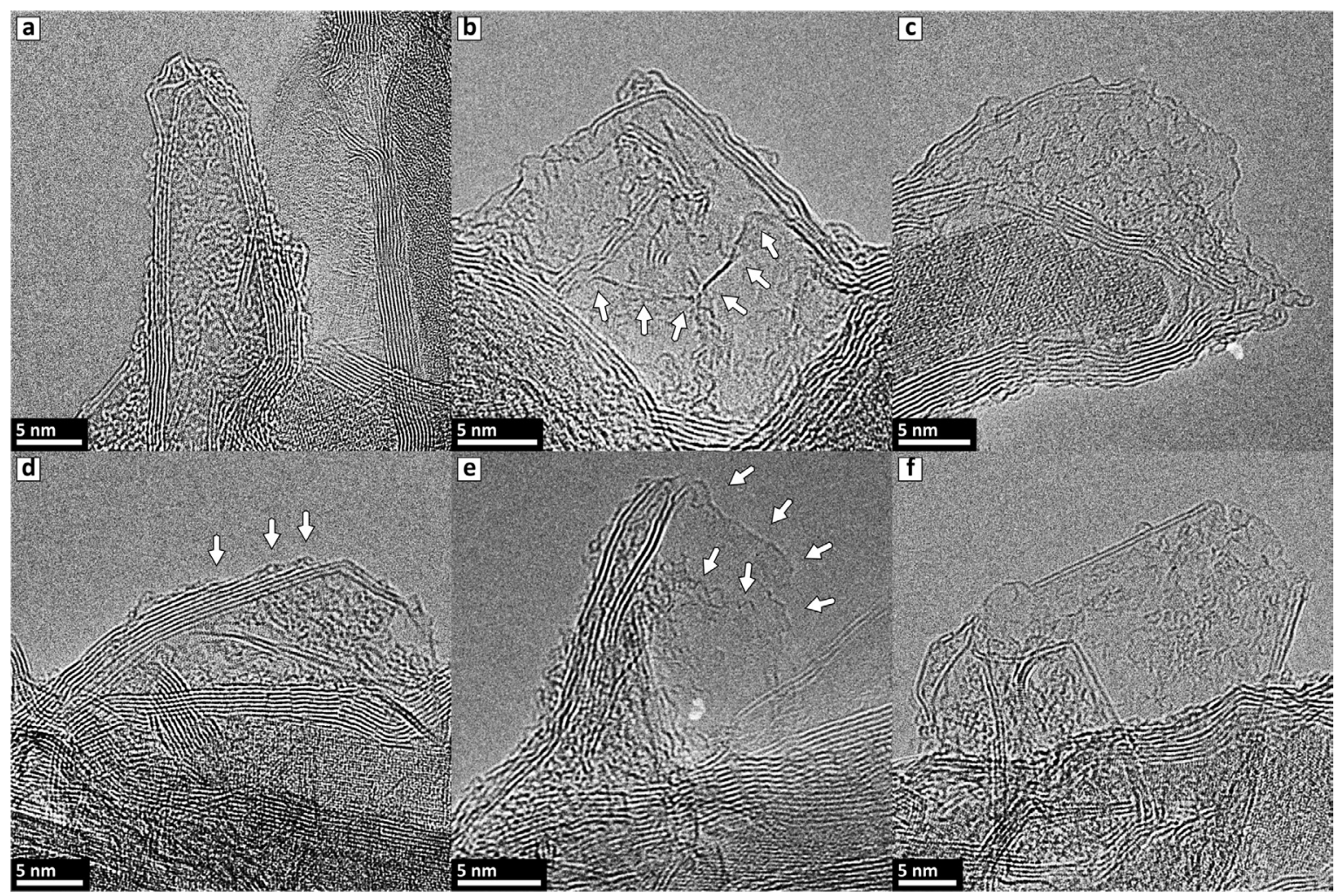

Fig. 6. HR-TEM micrographs of foliates from different locations (a-f). Arrows indicate the edges of layers.

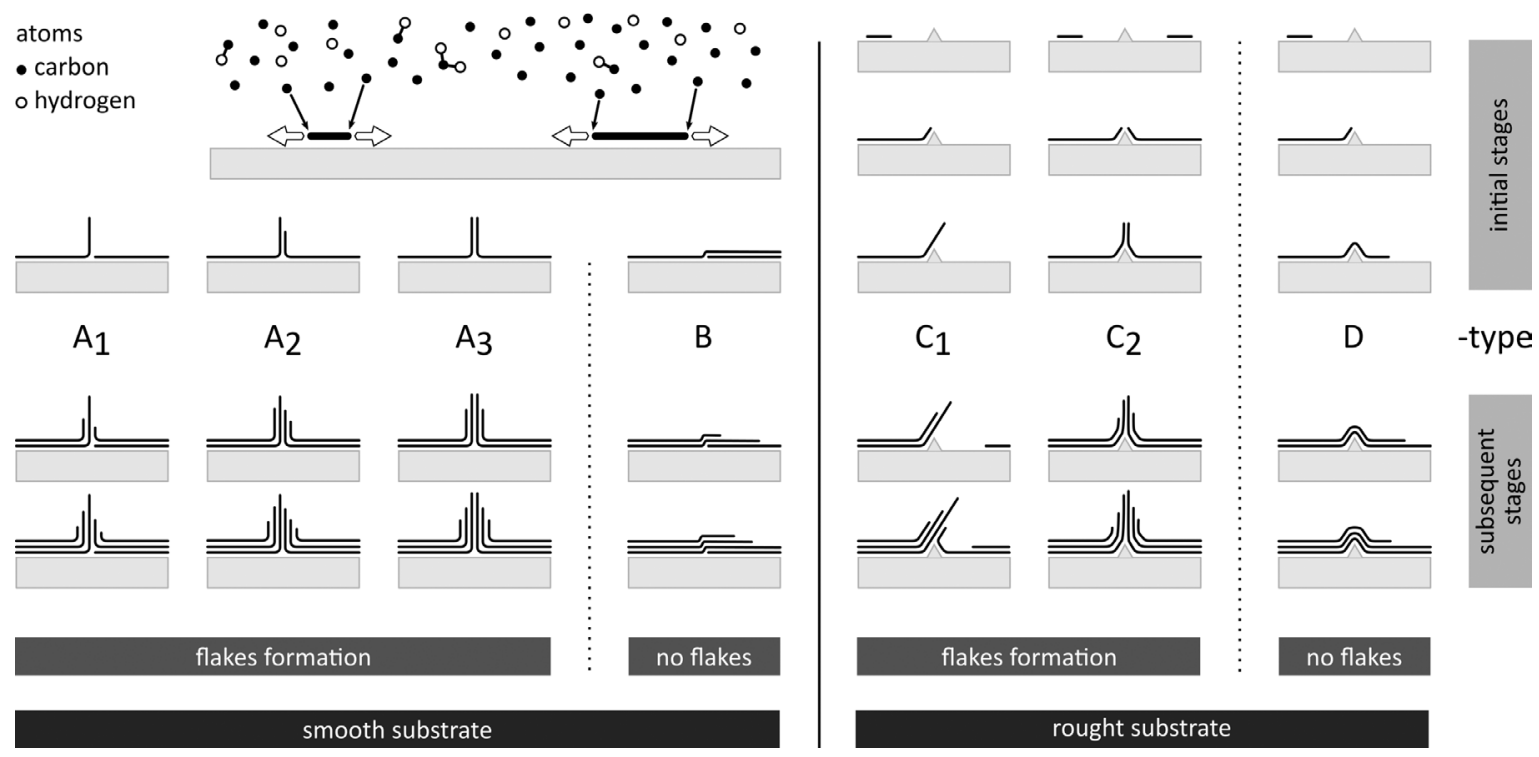

Fig. 7. Schematic of flake formation mechanisms. Stages of the deposition procedure are indicated in the right side of the figure. 


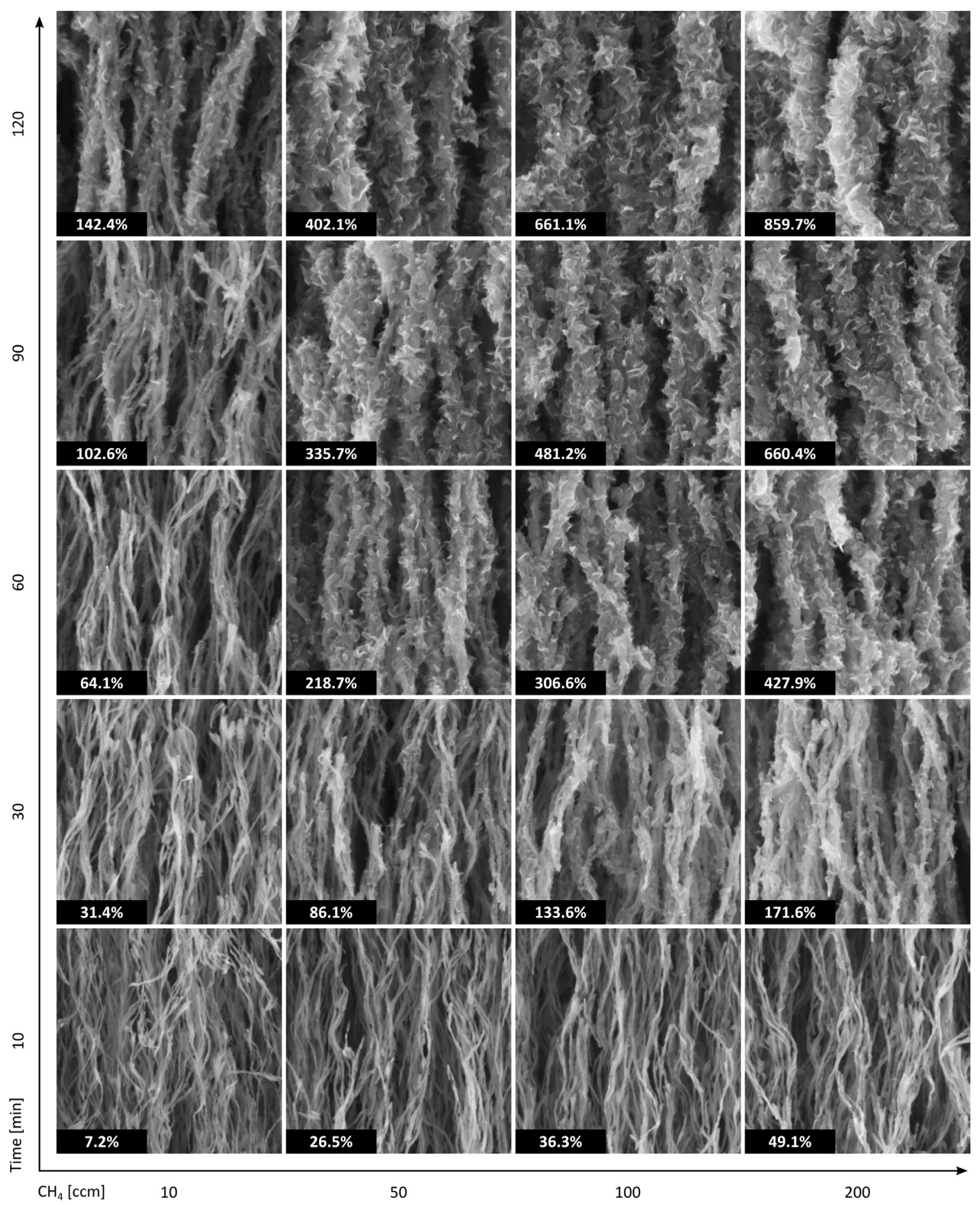

Fig. 8. HR-SEM images of the nanostructures. Coating weight is indicated inside a black rectangle, the width of this rectangle is $400 \mathrm{~nm}$. 


\subsection{Characterization}

The XPS analysis, which is detailed in [20], illustrates the fact that graphene augmented inorganic nanofibers (GAIN) are mainly composed of oxygen and carbon. XPS survey spectra reveal $\mathrm{C} 1 \mathrm{~s}$ and $\mathrm{O} 1 \mathrm{~s}$ as the most pronounced peaks. The sample of the low carbon content $(\Delta W=15 \%)$ generates two peaks associated with the binding energies of 74 and $119 \mathrm{eV}$, which are absent in other materials and relates to $\mathrm{Al} 2 \mathrm{p}$ and $2 \mathrm{~s}$ photoelectrons, [20].

The oxygen content is the lowest one for a highly graphenated nanostructure $(\Delta W=700 \%)$, thus indicating high carbon purity of the deposited coating. The $\mathrm{C} 1 \mathrm{~s}$ spectra exhibit a sharp peak at $284.3 \mathrm{eV}$ with additional contributions at higher binding energies, which can be ascribed as a trigonally bonded carbon ( $\mathrm{sp}^{2}$ centers), tetrahedrally bonded carbon ( $\mathrm{sp}^{3}$ centers), $\mathrm{C}-\mathrm{O} / \mathrm{C}=\mathrm{O}$ carbon, carboxylic acid groups, and $\pi-\pi^{*}$ shake-up peaks, respectively. Fibers covered by $2-5$ layers of graphene $(\Delta W=15 \%)$ have the lowest $\mathrm{sp}^{2}$ concentration $(63 \%)$ and the highest concentration of oxidized carbon centers (20\%). Therefore, at the early stages of deposition, the layer chemically interacts with the oxide support [20].

Fig. 9 demonstrates the spectra depicted from pure alumina, few-layered graphenated alumina, alumina coated by the foliated graphene; and MWCTs since alumina nanofibers encapsulated by graphene may be essentially described as a multiwalled carbon nanotube filled by ceramic nano-rod.

The characteristic peaks for graphene structures are $\mathrm{D}$ and $\mathrm{G}$ peaks at $\sim 1350$ and $\sim 1590 \mathrm{~cm}^{-1}$, respectively [21]. Additional peaks at 2680, 2930, and $3230 \mathrm{~cm}^{-1}$ represent characteristics of graphene layers [22]. A single symmetric peak at $2680 \mathrm{~cm}^{-1}$ indicates a few-layered graphene, as there is no splitting into an asymmetric doublet typical for graphite [22]; moreover, the relatively narrow bands
Taking into consideration insignificant change in the intensity of the $\mathrm{D}, \mathrm{G}$, and $2 \mathrm{D}$ peaks, and the ratio of ID/IG equal to $1.45 \pm 0.07$ for structures with a weight gain from 100 up to $900 \%$, an interrelation between graphene flakes evolution and Raman peaks was studied. In [58], free-standing graphene stacks of 2-20 layers was examined [23]. The observed peaks frequencies and shapes were found to be unique for the specific number of layers [23], and effect was repeatable at different energies of excitation photons, $E_{\text {exc }}=1.58 \mathrm{eV}(785 \mathrm{~nm}), 1.96 \mathrm{eV}(633 \mathrm{~nm})$, and $2.33 \mathrm{eV}(532 \mathrm{~nm})$. Fig. 10 represents the Raman response observed in the range $150-350 \mathrm{~cm}^{-1}$ in green and red excitation light and definitely testifies to the interrelations between the obtained peaks and modifications of coatings morphology.

Under a green laser, there are three discernible peaks can be found: the peak at $238.3 \mathrm{~cm}^{-1}$, at 269.5 $\mathrm{cm}^{-1}$, and $287 \mathrm{~cm}^{-1}$. With a help of the red laser, four peaks at $185.5 \mathrm{~cm}^{-1}, 213.7 \mathrm{~cm}^{-1}, 244.5 \mathrm{~cm}^{-1}$, and $290.5 \mathrm{~cm}^{-1}$ were found. Under the green light, a signal/noise ratio is poorer as compared to the red one, where the peaks are more recognizable and sharp. Excitation by red laser provides much lower noise but the peaks looks a bit suppressed. Only peaks 1 and 2 can be reliably allocated. Moreover, the peak 2 probably consists of two overlapping peaks. Predictably, it is hard to tie up the measured spectra with the results obtained on a high quality graphene with an exact number of layers; however, it can be used as an empirical correlation stimulated by flakes evolution.

\subsection{Applications of GAINs}

\subsubsection{Electrochemical energy conversion}

With the exhaustion of conventional energy sources, the need in renewable and efficient energy is continuously growing [24]. GAIN network is shown to serve as an excellent material for the electrochemical energy conversion due to presumably high electrical conductivity, chemical

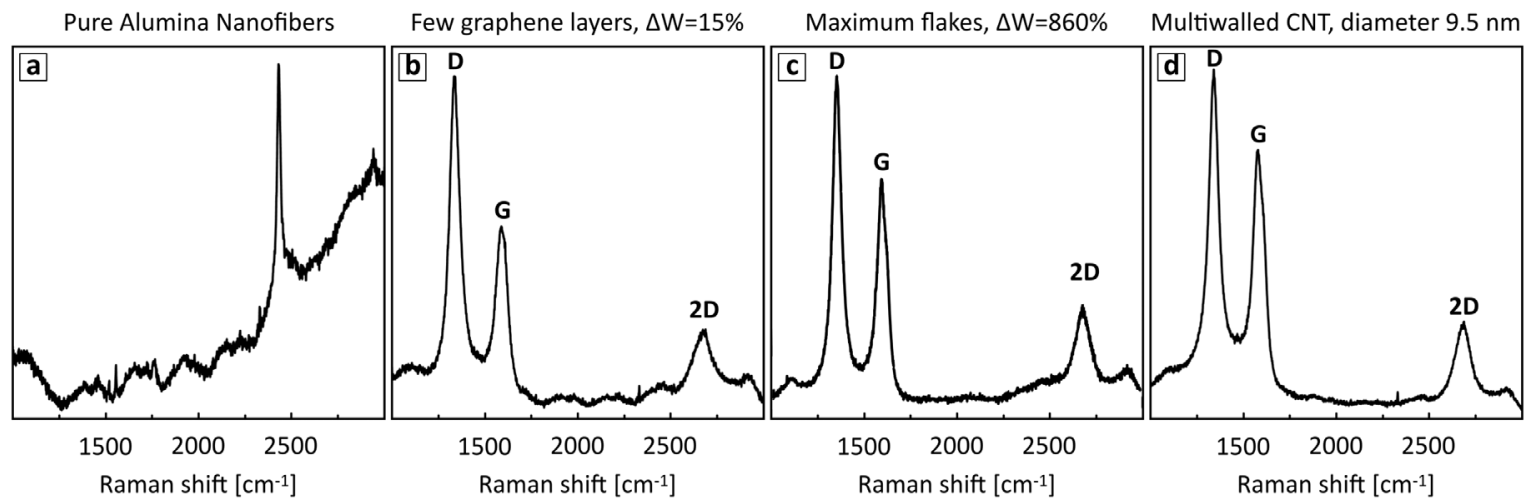

Fig. 9. Raman spectra of purified alumina nanofibers (a), slightly coated ( $\Delta W=15 \%)$ (b), and deposited by flakes near maximum ( $\Delta W=860 \%)(\mathrm{c})$; and commercially available MWCNT (d). 


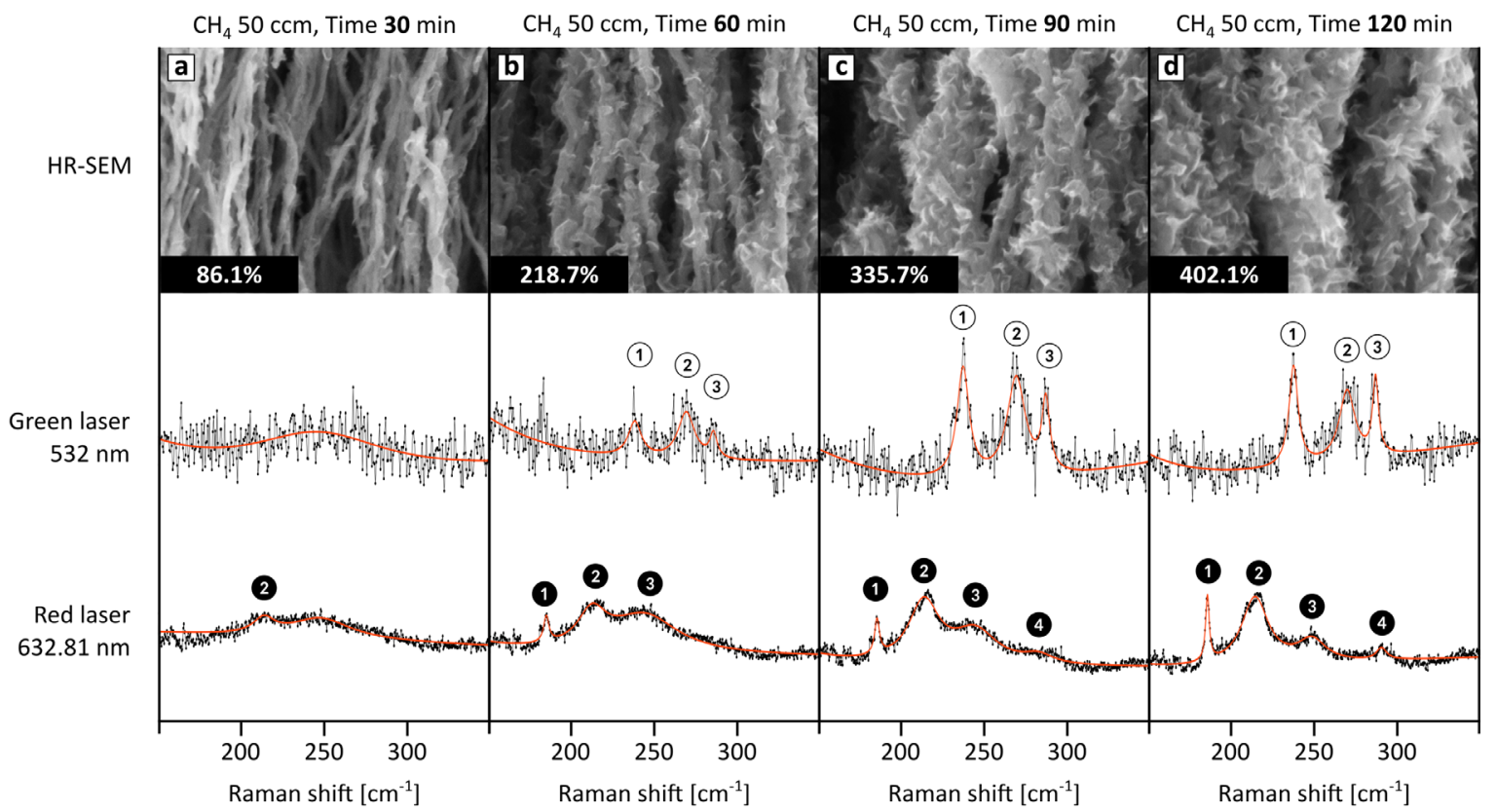

Fig. 10. Raman spectra of four samples obtained at two excitation energies $2.33 \mathrm{eV}$ (Green laser), and $1.96 \mathrm{eV}$ (Red laser) in the range $150-350 \mathrm{~cm}^{-1}$.

inertness, suitable durability, proper geometry allowing access to all catalyst particles, as well as a long time stability and reproducibility of functional characteristics [16]. The long-standing problem of agglomeration of the CNTs and/or graphene nanoplatelets has been solved through the presence of the rigid fibers providing the 3D architecture and the high level of porosity.

In [16], the detailed analysis of the prepared substrate covered by 1-3 layers of graphene and decorated by $\mathrm{Pt}$ (Fig. 11a) is provided demonstrating that the electrochemical surface area (ESA) is in the range of 0.05-0.4 VRHE for the developed material, which is larger than the reported for commonly used $\mathrm{Pt} / \mathrm{C}$.
The difference in the potential at a half current between $\mathrm{Pt} / \mathrm{ANFC}$ and $\mathrm{Pt} / \mathrm{C}$ is around $22 \mathrm{mV}$. Therefore, a smaller driving force is needed to reduce the oxygen. Fig. 11b displays a specific activity and a mass activity specified from the kinetic current obtained at $1600 \mathrm{rpm}$ in $\mathrm{O}_{2}$ saturated $0.1 \mathrm{M} \mathrm{HClO}_{4}$ and ECSA [16].

Good stability is explained by the relatively high (75\%) content of the $\mathrm{sp}^{2}$ hybridized carbon atoms, while for an activated carbon, the $\mathrm{sp}^{3}$ hybridization is typical, and the electrochemical degradation of carbon is more prone at $\mathrm{sp}^{3}$ sites rather than at $\mathrm{sp}^{2}$ [25]. The graphene encapsulated and platinizing hybrid fibers network has a straightforward applications in imminent catalyst nanostructures.
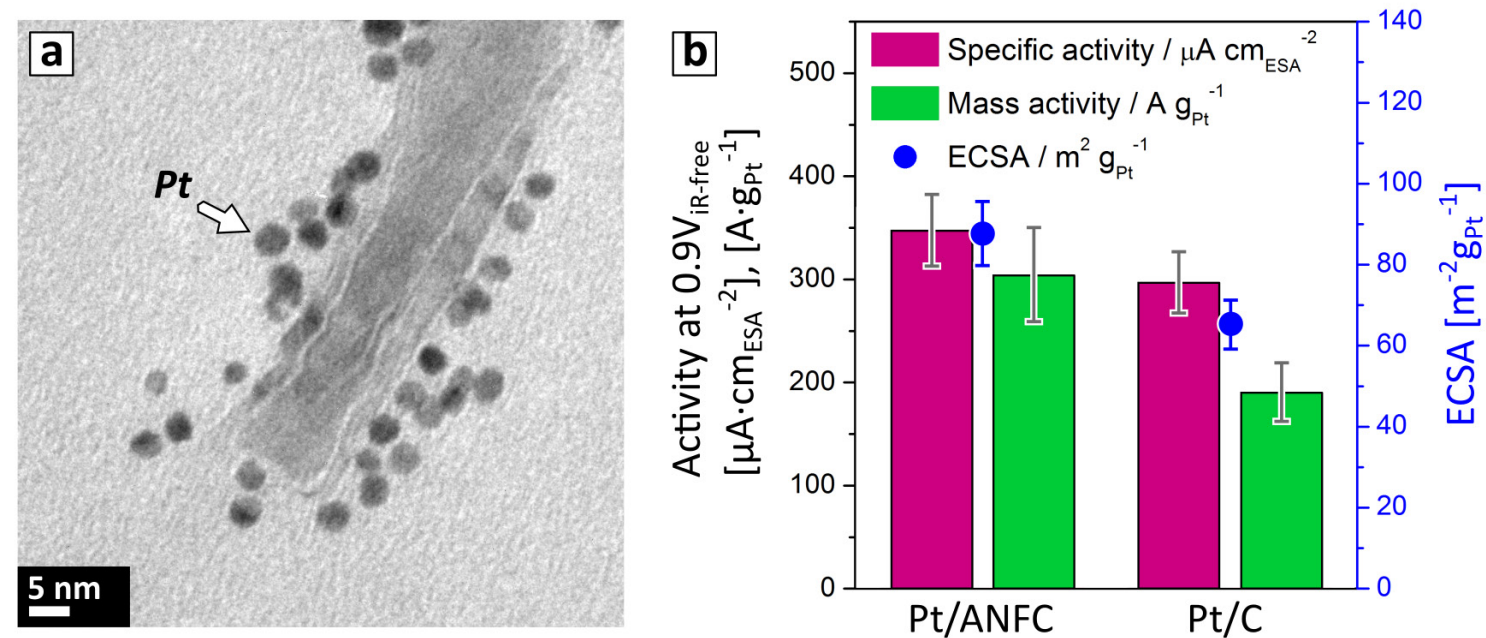

Fig. 11. TEM observations of Pt nanoparticles on the surface of GAIN (a). Comparison of mass and surface activity of Pt/ANFC and Pt/C (b). Adapted from [16]. 


\subsubsection{Electroconductive fillers for composites}

The research area of graphene added composites is now quite mature [26-28]. However, the benefits offered by nanocarbon-based fillers is hindered by problems with agglomeration and poor dispersity throughout the host matrix. For the first time, the novel approach to electroconductive nano-fillers for otherwise dielectric materials has been proposed in [15]. The thermal analysis and Raman spectroscopy of the graphenated alumina nanofibers produced with no foliates on the several graphene layers are detailed in $[15,16]$. Raman spectrum, obtained from the fibers subjected to ball milling, confirms integrity of the carbon layers on the surface. Four well-recognized peaks around $1340 \mathrm{~cm}^{-1}, 1600 \mathrm{~cm}^{-1}$, $2680 \mathrm{~cm}^{-1}$, and $2930 \mathrm{~cm}^{-1}$ are clearly identified together with an additional weak peak at $3180 \mathrm{~cm}^{-1}$, Fig. 12. Relatively narrow bands point to the nanocrystalline structure of the carbon.

The dried suspension of the alumina and fillers represents a homogeneous mixture of the nanofibers within the ceramic matrix, Fig. 12, providing a clear evidence of good dispersion of the nanofibers within the matrix. The alumina and partially stabilized zirconia based nanocomposites were consolidated by spark plasma sintering technique as described in $[15,29,30]$. Sintered materials demonstrated significant increase in electroconductivity at as low load of graphene as 0.3 wt.\% for aluminabased composites and 0.34 wt. $\%$ for zirconia based composites. This fact confirms the feasibility of the developed nanostructures of the graphenated alumina nanofibers as nanofillers for enhancing electrical response of otherwise dielectric ceramic matrices.

Moreover, the strategy allows fabrication of materials of functional gradients and controlled anisotropy [31,32]. For example, layered alumina, where layers of pure alumina and GAINs are alternating, demonstrates the directional electrical and thermal conductivity. A graphene-containing interlayer with $50 \mu \mathrm{m}$ thickness, sandwiched between two monolithic $10 \mathrm{~mm}$ layers of alumina shows $\sim 30 \%$ enhancement in isotropic thermal conductivity of monolithic alumina [31]. The electronic contribution of the thermal transport is negligible and the main mechanism for thermal transport is phonon scattering. Electrons are the dominant carriers in the graphene augmented nanofillers, however in the composites, strong p-doping of alumina matrix resulted in p-type conduction [32]. The developed layered structures enable engineering of lightweight electronics enclosures where anisotropic properties can enable multifunctionality such as electrostatic charge dissipation and electromagnetic interference shielding, while thermal conductivity is a critical concern. Control of the process parameters, thickness and amount of GAIN fillers, allows tuning the electrical response, which can help designing functional materials with potential application in areas such as EMI-shielding for electronics and aerospace.

\subsubsection{Scaffolds for bio-applications}

Micro-environmental control of stem cell fate is of primary importance in tissue engineering and regenerative medicine. Recently it was proved that topography of the culture substrate or scaffold may affect stem cell differentiation. The highly aligned 3D network represents a great opportunity for tissue engineering [33]. Currently, there are three major ways to fabricate nanofibrous scaffolds: selfassembly, electrospinning, and phase separation. Each has its own processing capabilities, advantages, and disadvantages. The developed substrates for cells differentiation and growth based on the biocompatible and chemically stable network of GAIN represents the significant breakthrough in biotechnology. Graphenecoated surfaces have been shown to accelerate cell adhesion and proliferation of mesenchymal stem cells (MSC) into osteocytes [34] and adipocytes [35]. MSCs were committed towards cardiomyogenic lineage by culturing them on graphene by regulated expression of extra-cellular matrix and signalling molecules [36]. Unique composition and structure of the GAIN scaffolds allows changes in microenvironment making fibrous substrates.
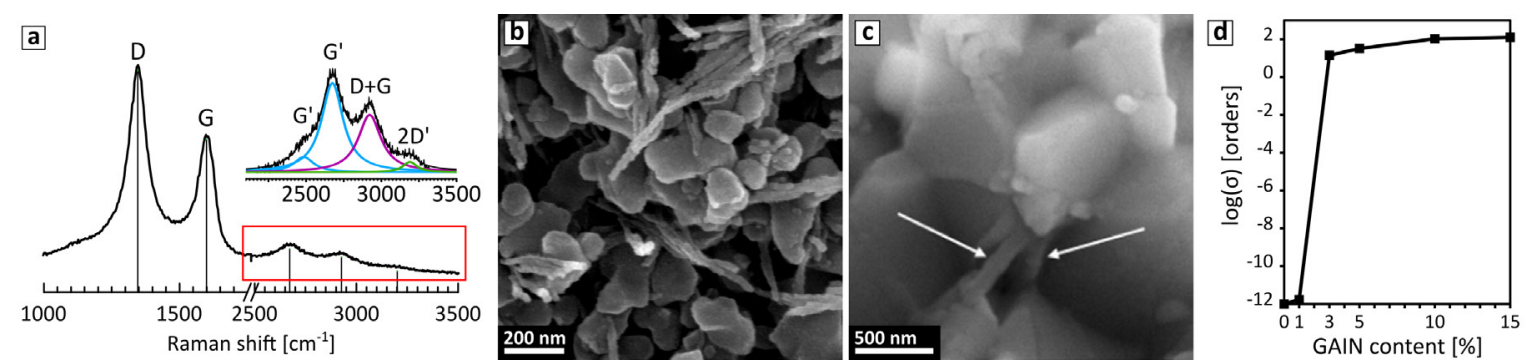

Fig. 12. Raman spectra of GAINs after milling (a), mixture of alumina and GAINs, fractured surface of the composite (the fibers are pointed by arrows) (c), and dependence of electro-conductivity on fibers content in alumina (d). 
Using GAIN scaffolds, an efficient neuronal differentiation of the stem cells has been demonstrated for the first time. Fig. 13 schematically shows specifically oriented supports for cells growth. The horizontal orientation of the fibers tolerates preferable orientation and varying morphology of different types of cells [37]. New GAIN scaffolds represent a novel biocompatible material capable of direct facilitation of MSC attachment, proliferation and early guidance of cell spontaneous differentiation towards neural lineages, just due to its topo-mechanical features. Facing highly anisotropic substrate, a number of contradictory messages may be transduced into the nucleus via cell cytoskeleton and membrane tension and cells react in a unique way which is impossible if cells grow in plane.

The vertical orientation of the fibers in the scaffold allows development of mixed tumour model [38]. This assertively causes different expression of respective oncogenes and tumor suppressor genes.

\subsubsection{Sensors for bio-analytes}

Ascorbic acid (AA), dopamine (DA), and uric acid (UA) are compounds of primary importance in bioand medical sciences. All these bio-molecules play a fundamental role in human metabolism [39] and coexist in physiological fluids [40]. Ascorbic acid is a powerful antioxidant needed to cure cancer, scurvy, colds, and many other diseases [41]; dopamine is one of the most vital neurotransmitters controlling functions of the central nervous system [42]; uric acid is the primary product of purine metabolism indicating gout, hyperuricemia and other diseases [43].
The development of a technique for simultaneous detection of all three compounds is essential for diagnose of relevant health problems. However, the electrochemical oxidation potentials of AA, DA, and UA are overlapped and responses are influenced by the presence of other bio-species [44]. Extensive efforts have been made in order to overcome these problems $[45,46]$. Carbon nanostructures and, especially, graphene have shown remarkable charge-transfer properties and suitable chemical stability [47].

Combination of unique electronic properties of graphene with a large surface area of self-organized nanofibers allows production of a sensor for effective simultaneous determination of bio-analytes. Sensors were prepared out of highly foliated graphene deposited onto fibers and thoroughly tested for electrochemical response using cyclic voltammetry and differential pulse voltammetry (DPV) a substrate with calculated density of foliates of $50 \pm$ 10 per micron length of the fiber has demonstrated the voltammetric responses of well-defined and resolved oxidation peaks at $-60 \mathrm{mV}, 210 \mathrm{mV}$, and $320 \mathrm{mV}$ for $\mathrm{AA}, \mathrm{DA}$, and UA, respectively, demonstrating a good selective electrocatalytic performance and perspective to be successfully used for the simultaneous detection of three biospecies, Fig. 14, [46,48]. The sensitivity measured by differential pulse voltammetry was found to be $0.59 \mu \mathrm{M}, 0.47 \mu \mathrm{M}$, and $0.28 \mu \mathrm{M}$ for ascorbic acid, dopamine, and uric acid, respectively [48].

Transition metals such as $\mathrm{Cu}$ nano-particles (NP) can further improve charge and mass transfer of the
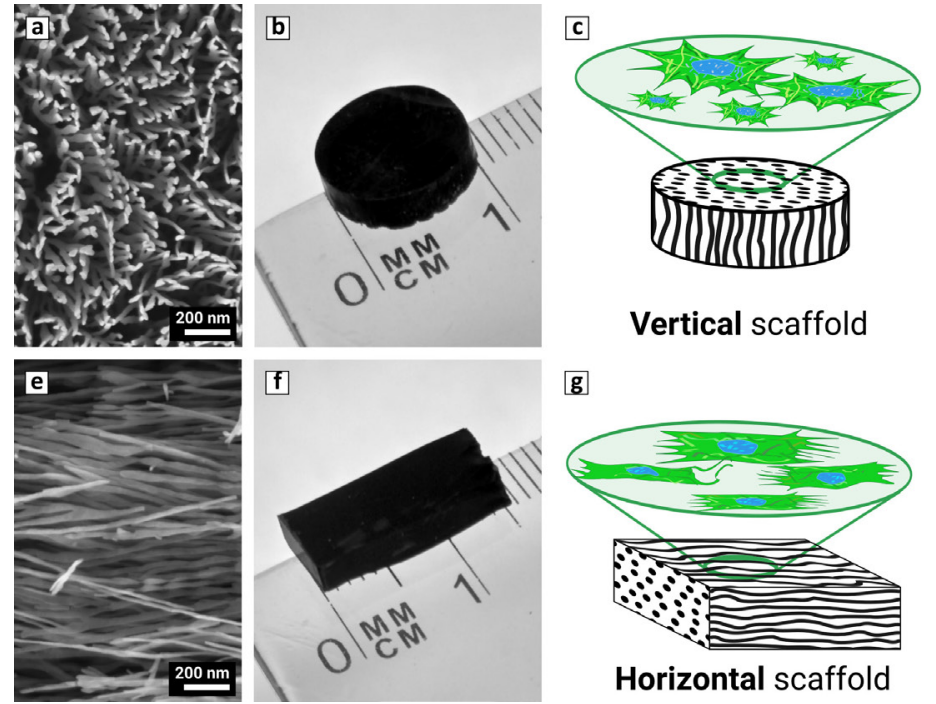

Vertical scaffold

g

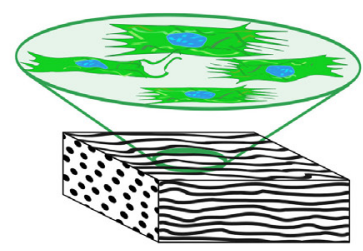

Horizontal scaffold
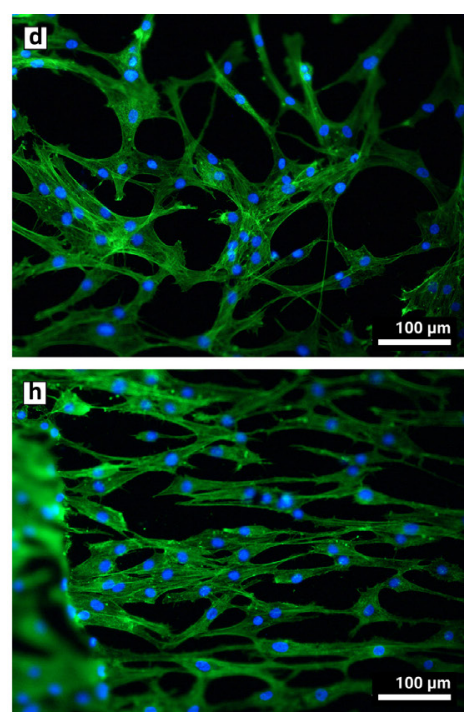

Fig. 13. Top view of scaffold (a), general view of vertical scaffold (b), vertical scaffold sketch with tumor cells (c), immunofluorescence images of cancer cells on vertical scaffold (d), side view of scaffold (e), general view of horizontal scaffold (f), horizontal scaffold sketch with human mesenchymal stem cells (hMSC) (g), immunofluorescence images of MSCs grown on horizontal GAIN for 3 days (h). 

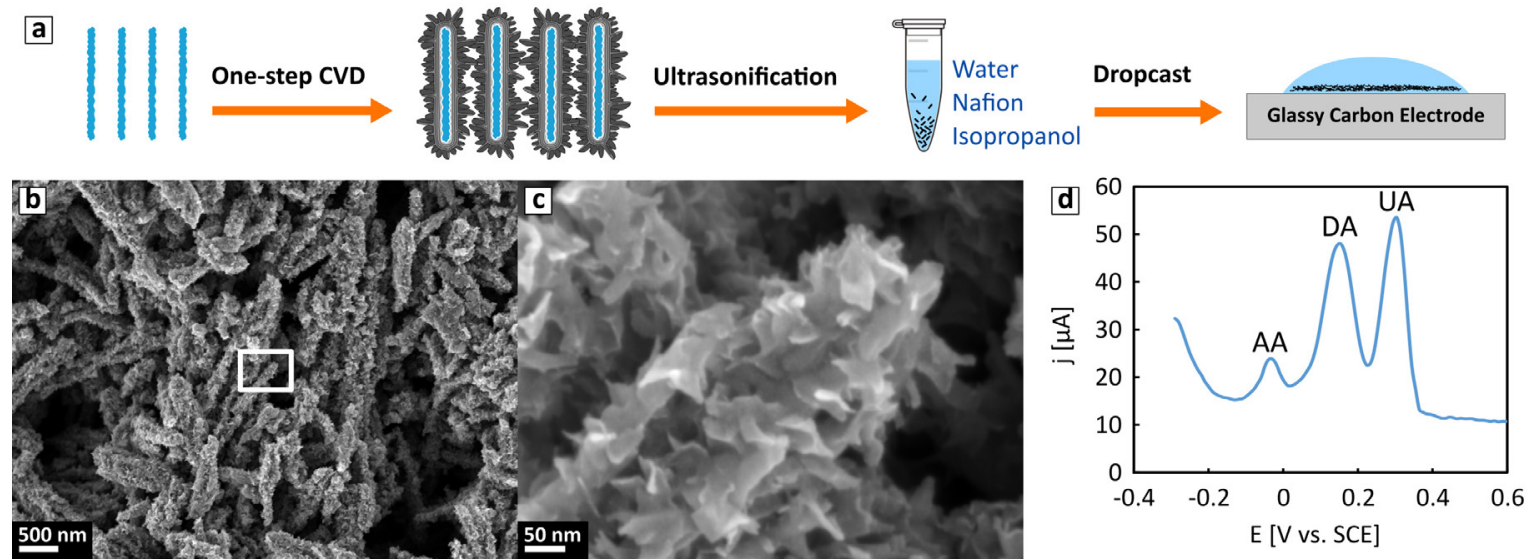

Fig. 14. Sketch of the process of sensor fabrication (a), fibers covered by foliated graphene (b, c), DPV profile measured in ternary mixture of AA, UA and DA (d).

network of GAINs resulting at even better sensitivity due to its multiple oxidation states and further increase in surface area. It have been demonstrated that graphene-NP combination can act synergistically to offer unique physicochemical properties.

Efficiency of catalyst is determined by a low overpotential, high electrical activity, suitable stability, robustness, and cost-effectiveness of production. One of the ways for preparation of advanced $\mathrm{Cu}$ based nanomaterials is anchoring $\mathrm{Cu}$ NPs on a support of carbon-based network. The interactions between the NPs and carbon may have profound effect on the resulting physical and chemical properties of the system $[49,50]$. Therefore, the development and application of alumina/graphene/ copper hybrid sensor can allow the simultaneous detection of acetaminophen (AP, paracetamol), epinephrine (EP, adrenaline), and tryptophan (Trp).

Electrochemically deposited particles of nanocopper onto GAINs as detailed in [51] resulted in the synergistic effects of graphene- $\mathrm{Cu}$ hybrid structures on overall performance of the electrode towards EP, AP, and Trp in their individual and simultaneous determination. The collected data demonstrated the linear calibration curves and the outstanding instrumental detection limits of $0.027,0.012$, and $0.009 \mu \mathrm{M}$ for EP, AP, and Trp, respectively. Fig. 15 shows morphology of decorated GAINs and CVs of bare GCE, GAIN, and GAIN/Cu in $0.1 \mathrm{M}$ phosphate buffer ( $\mathrm{pH}$ 6.0) alongside with linear relationships between current and square root of scan rate for GAIN/Cu for different analytes. This validates the analytical utility of the GAIN/ $\mathrm{Cu}$ chemo-sensor. The GAIN/Cu electrochemical sensor with a good stability and repeatability can be an appropriate candidate for the pharmaceutical applications and clinical investigations.

\section{CONCLUSIONS}

The present review is concentrated on the development of a cost-effective and environmentally friendly method of graphene growth on arbitrary ceramic surfaces at atmospheric pressure and relatively low temperatures by procedure. The developed CVD procedure allows controllable deposition of carbon with tailored morphology, starting from a few layered smooth coatings and ending by highly foliated fuzzy nanostructures. The material which offers tailorable density of graphitic edges, which is needed for a highly stable electrocatalyst support has been offered. The graphene encapsulated nanofibers have been used as fillers for manufacturing electroconductive ceramics with no deterioration in mechanical properties. Unique properties of scaffolds, based on graphenated nanostructures, have been used to provide an improved capacity in enhancing human mesenchymal stem cells alignment without any additional manipulations and a possible cells differentiation fate. The outstanding electrochemical stability of the platinized graphene encapsulated fibers and an improvement in the mass activity have confirmed applicability of the structures for electrochemical applications. The alumina nanofibers encapsulated by highly foliated multilayered graphene have been used for a simultaneous detection of ascorbic and uric acids together with dopamine. The developed sensor has demonstrated the superior electrocatalytic activities providing excellent selectivity and low detection limits towards this ternary mixture. The developed alumina/graphene/copper hybrid sensor allows the simultaneous detection of acetaminophen (AP, paracetamol), epinephrine (EP, adrenaline), and tryptophan (Trp). 

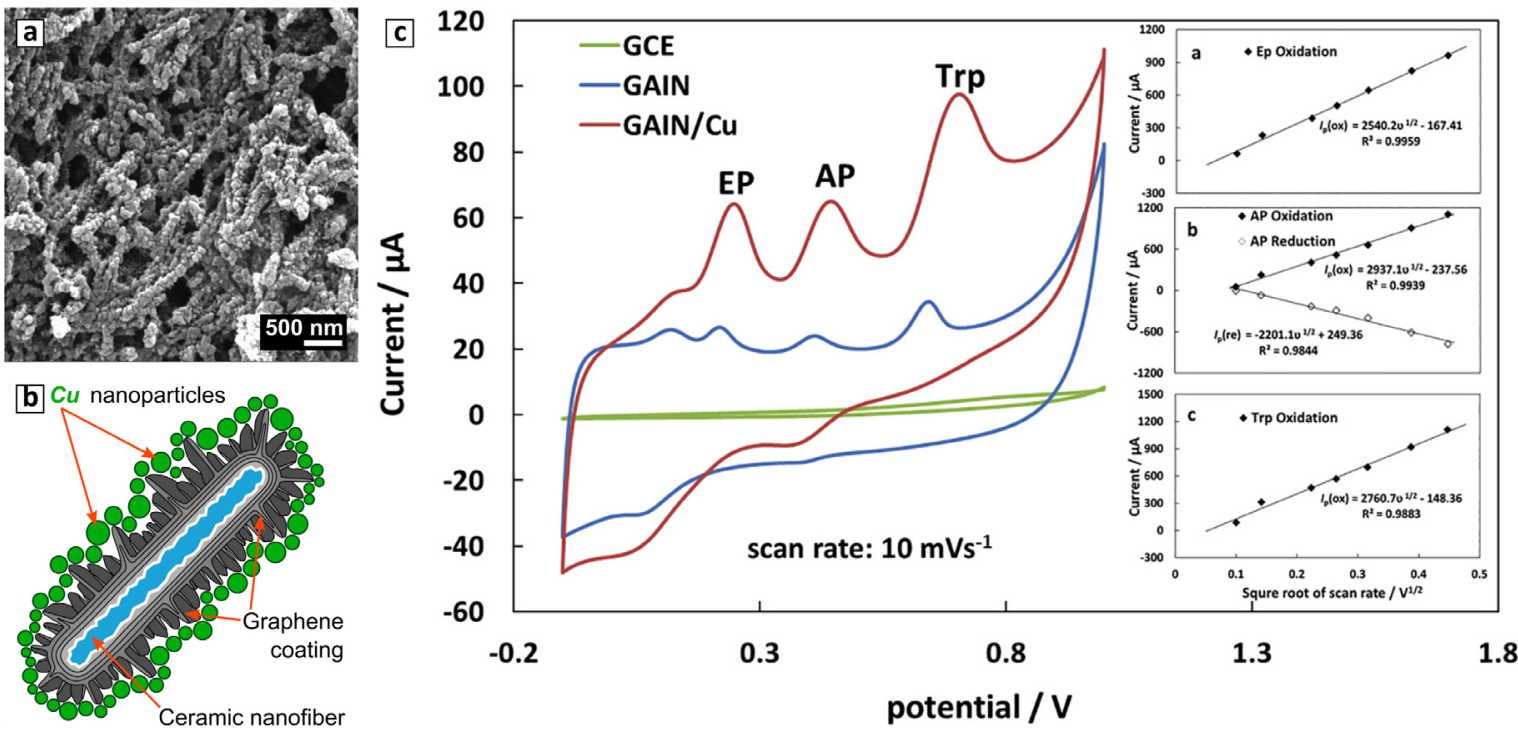

Fig. 15. SEM image of GAIN modified glassy carbon electrode (a); sketch of the single graphenated fiber decorated by copper nanoparticles (b); and CVs of bare GCE (green), GAIN (blue) and GAIN/Cu (red) in $0.1 \mathrm{M}$ phosphate buffer ( $\mathrm{pH}$ 6.0) containing $200 \mu \mathrm{M} \mathrm{EP}, 100 \mu \mathrm{M} \mathrm{AP}$, and $100 \mu \mathrm{M}$ Trp at $10 \mathrm{mV} \mathrm{s}-1$. Insets show linear relationships between current and square root of scan rate for $\mathrm{GAIN} / \mathrm{Cu}$ for different analytes (d).

\section{ACKNOWLEDGEMENTS}

This work was supported by the Estonian Research Council grant PRG643 (I. Hussainova). The authors would like to acknowledge the help of $\mathrm{PhD}$ Olga Volobujeva from Department of Materials and Environmental Technology Engineering, TalTech, for SEM imaging.

\section{REFERENCES}

[1] M.I. Fadlalla, P.S. Kumar, V. Selvam and S.G. Babu, Emerging energy and environmental application of graphene and their composites: a review, J. Mater. Sci., 2020, vol. 55, pp. 71567183. https://doi.org/10.1007/s10853-020-04474-0

[2] A. Bianco, H.-M. Cheng, T. Enoki, Y. Gogotsi, R.H. Hurt, N. Koratkar, T. Kyotani, M. Monthioux, C.R. Park, J.M. Tascon and J. Zhang, All in the graphene family $-A$ recommended nomenclature for twodimensional carbon materials, Carbon, 2013, vol. 65, pp 1-6. https://doi.org/10.1016/j. carbon.2013.08.038

[3] K.S. Novoselov, A.K. Geim, S.V. Morozov, D. Jiang, Y. Zhang, S.V. Dubonos, I.V. Grigorieva and A.A. Firsov, Electric Field Effect in Atomically Thin Carbon Films, Science, 2004, vol. 306, no. 5696, pp. 666-669. https://doi.org/10.1126/science.1102896

[4] A. Sakhaee-Pour, Elastic properties of singlelayered graphene sheet, Solid State Commun., 2009, vol. 149, no. 1-2, pp. 91-95. https://doi. org/10.1016/j.ssc.2008.09.050
[5] S. Goenka, V. Sant and S. Sant, Graphenebased nanomaterials for drug delivery and tissue engineering, J. Controlled Release, 2014, vol. 173, pp. 75-88. https://doi.org/10.1016/j. jconrel.2013.10.017

[6] P.R. Somani, S.P. Somani and M. Umeno, Planer nano-graphenes from camphor by CVD, Chem. Phys. Lett., 2006, vol. 430, no. 1-3, pp. 56-59. https://doi.org/10.1016/ j.cplett.2006.06.081

[7] Z.-S. Wu, W. Ren, L. Gao, B. Liu, C. Jiang and H.-M. Cheng, Synthesis of high-quality graphene with a pre-determined number of layers, Carbon, 2009, vol. 47, no. 2, pp. 493-499. https://doi.org/10.1016/j.carbon.2008.10.031

[8] Y. Zhang, L. Zhang and C. Zhou, Review of Chemical Vapor Deposition of Graphene and Related Applications, Acc. Chem. Res., 2013, vol. 46, no. 10, pp. 2329-2339. https://doi.org/10.1021/ar300203n

[9] A. Ismach, C. Druzgalski, S. Penwell, A. Schwartzberg, M. Zheng, A. Javey, J. Bokor and Y. Zhang, Direct Chemical Vapor Deposition of Graphene on Dielectric Surfaces, Nano Lett., 2010, vol. 10, no. 5, pp. 1542-1548. https://doi.org/10.1021/n19037714

[10] K. Yu, G. Lu, Z. Bo, S. Mao and J. Chen, Carbon Nanotube with Chemically Bonded Graphene Leaves for Electronic and Optoelectronic Applications, J. Phys. Chem. Lett., 2011, vol. 2, no. 13, pp. 1556-1562. https://doi.org/10.1021/jz200641c 
[11] C.B. Parker, A.S. Raut, B. Brown, B.R. Stoner and J.T. Glass, Three-dimensional arrays of graphenated carbon nanotubes, J. Mater. Res., 2012, vol. 27, no. 7, pp. 10461053. https://doi.org/10.1557/jmr.2012.43

[12] J. Zheng, X., Ma, X. He, M. Gao and G. Li, Praparation, characterizations, and its potential applications of PANi/ graphene oxide nanocomposite, Procedia Eng., 2012, vol. 27, pp. 1478-1487. https://doi.org/10.1016/j.proeng.2011.12.611

[13] M. Aghayan, I. Hussainova, M. Gasik, M. Kutuzov and M. Friman, Coupled thermal analysis of novel alumina nanofibers with ultrahigh aspect ratio, Thermochim. Acta, 2013, vol. 574, pp. 140-144. https://doi. org/10.1016/j.tca.2013.10.010

[14] R. Ivanov, V. Mikli, J. Kubarsepp and I. Hussainova, Direct CVD growth of foliated graphene close shells on alumina nanofibers, Key Eng. Mat., 2016, vol. 674, pp. 77-80. https://doi.org/10.4028/www.scientific.net/ KEM.674.77

[15] R. Ivanov, I. Hussainova, M. Aghayan, M. Drozdova, D. Perez-Coll, M.A. Rodriguez and F. Rubio-Marcos, Graphene encapsulated oxide nanofibers as a novel type of nanofillers for electroconductive ceramics, J. Eur. Ceram. Soc., 2015, vol. 35, no. 14, pp. 4017-4021. http://dx.doi.org/10.1016/j. jeurceramsoc.2015.06.011

[16] I. Hussainova, R. Ivanov, S.N. Stamatin, I.V. Anoshkin, E.M. Skou and A.G. Nasibulin, A few-layered graphene on alumina nanofibers for electrochemical energy conversion, Carbon, 2015, vol. 88, pp. 157164. https://doi.org/10.1016/j.carbon.2015.03.004

[17] F. Bonaccorso, L. Colombo, G. Yu, M. Stoller, V. Tozzini, A.C. Ferrari, R.S. Ruoff and V. Pellegrini, Graphene, related twodimensional crystals, and hybrid systems for energy conversion and storage, Science, 2015, vol. 347, no. 6217, pp. 1246501-1246501. https://doi.org/10.1126/science.1246501

[18] T. Masoud, R. Ivanov, S. Bereznev, S.H. Kazemi and I. Hussainova, Ultrasensitive voltammetric simultaneous determination of dopamine, uric acid and ascorbic acid based on a graphene-coated alumina electrode, Microchim. Acta, 2017, vol. 184, pp. 4603-4610. https://doi. org/10.1007/s00604-017-2510-y

[19] S.M. Ubnoske, A.S. Raut, B. Brown, C.B. Parker, B.R. Stoner and J.T. Glass, Perspectives on the Growth of High Edge Density Carbon Nanostructures: Transitions from Vertically Oriented Graphene Nanosheets to Graphenated Carbon Nanotubes, J. Phys.
Chem. C Nanomater. Interfaces, 2014, vol. 118, no. 29, pp. 16126-16132. https://doi. org/10.1021/jp502317u

[20] S.N. Stamatin, I. Hussainova, R. Ivanov and P.E. Colavita, Quantifying graphitic edge exposure in graphene based materials and its role in oxygen reduction reactions, ACS Catal., 2016, vol. 6, no. 8, pp. 5215-5221. https://doi.org/10.1021/acscatal.6b00945

[21] A.C. Ferrari, Raman spectroscopy of graphene and graphite: Disorder, electron-phonon coupling, doping and nonadiabatic effects, Solid State Commun., 2007, vol. 143, no. 1-2, pp. 47-57. https://doi.org/10.1016 ssc. 2007.03 .052

[22] A.C. Ferrari and D.M. Basko, Raman spectroscopy as a versatile tool for studying the properties of graphene, Nat. Nanotechnol., 2013, vol. 8, no. 4, pp. 235-246. https://doi. org/10.1038/nnano.2013.46

[23] C.H. Lui and T.F. Heinz, Measurement of layer breathing mode vibrations in few-layer graphene, Phys. Rev. B: Condens. Matter., 2013, vol. 87, no. 12, art. 121404. https://doi. org/10.1103/PhysRevB.87.121404

[24] H.-J. Choi, S.-M. Jung, J.-M. Seo, D.W. Chang, L. Dai and J.-B. Baek, Graphene for energy conversion and storage in fuel cells and supercapacitors, Nano Energy, 2012, vol. 1, no. 4, pp. 534-551. https://doi. org/10.1016/j.nanoen.2012.05.001

[25] J. Speder, A. Zana, I. Spanos, J.J. Kirkensgaard, K. Mortensen and M. Arenz, On the influence of the Pt to carbon ratio on the degradation of high surface area carbon supported PEM fuel cell electrocatalysts, Electrochem. Commun., 2013, vol. 34, pp. 153-156. https://doi. org/10.1016/j.elecom.2013.06.001

[26] I. Hussainova, M. Drozdova, D. Pérez-Coll, F. Rubio-Marcos, I. Jasiuk, J.A. Soares, M.A. Rodríguez, Hierarchically structured zirconia reinforced by hybrid graphenel alumina nanofibers, J. Eur. Ceram. Soc., 2017, vol. 37, no. 12, pp. 3713-3719. https://doi. org/10.1016/j.jeurceramsoc.2016.12.033

[27] A. Nieto, A. Bisht, D. Lahiri, C. Zhang and A. Agarwal, Graphene reinforced metal and ceramic matrix composites: a review, Int. Mater. Rev., 2017, vol. 62, no. 5, pp. 241-302. https://doi.org/10.1080/09506608.2016.1219481

[28] A. Gómez-Gómez, C. Ramírez, J. Llorente, A. Garcia, P. Moreno, H. Reveron, J. Chevalier, M.I. Osendi, M. Belmonte and P. Miranzo, Improved crack resistance and thermal conductivity of cubic zirconia containing graphene nanoplatelets, J. Eur. Ceram. Soc., 2020, vol. 40, no. 4, pp. 1557-1565. https://doi. org/10.1016/j.jeurceramsoc.2019.12.016 
[29] M. Drozdova, I. Hussainova, D. Pérez-Coll, M. Aghayan, R. Ivanov and M.A. Rodríguez, A novel approach to electroconductive ceramics filled by graphene covered nanofibers, Mater. Des., 2016, vol. 90, pp. 291-298. https://doi. org/10.1016/j.matdes.2015.10.148

[30] I. Hussainova, J. Baronins, M. Antonov and M. Drozdova, Wear performance of hierarchically structured alumina reinforced by hybrid graphene encapsulated alumina nanofibers, Wear, 2016, vol. 368-369, pp. 287295. https://doi.org/10.1016/j.wear.2016.09.028

[31] I. Hussainova, A. Saffar Shamshirgar, R. Ivanov, O. Volobujeva, A.E. Romanov and M. Gasik, Directional conductivity in layered alumina, Curr. Appl Phys., 2020, in press. https:// doi.org/10.1016/j.cap.2020.06.009

[32] A. Saffar Shamshirgar, R.E. Rojas-Hernandez, G. Tewari, R. Ivanov, V. Mikli, M. Karppinen and I. Hussainova, Multi-Functional Layered Structure of Alumina/Graphene-AugmentedNanofibers with Directional Conductivity, Carbon, 2020, vol. 167, pp.634-645. https://doi. org/10.1016/j.carbon.2020.06.038

[33] P.A. Madurantakam, C.P. Cost, D.G. Simpson and G.L. Bowlin, Science of nanofibrous scaffold fabrication: strategies for next generation tissueengineering scaffolds, Nanomedicine, 2009, vol. 4, no. 2, pp. 193-206. https://doi.org/10.2217/ 17435889.4.2.193

[34] H. Elkhenany, L. Amelse, A. Lafont, S. Bourdo, M. Caldwell, N. Neilsen, E. Dervishi, O. Derek, A.S. Biris, D. Anderson and M. Dhar, Graphene supports in vitro proliferation and osteogenic differentiation of goat adult mesenchymal stem cells: potential for bone tissue engineering, J. Appl. Toxicol., 2015, vol. 35, no. 4, pp. 367374. https://doi.org/10.1002/jat.3024

[35] W.C. Lee, C.H.Y.X. Lim, H. Shi, L.A.L.Tang, Y. Wang, C.T. Lim and K.P. Loh, Origin of enhanced stem cell growth and differentiation on graphene and graphene oxide, ACS Nano, 2011, vol. 5, no. 9, pp. 7334-7341. https://doi. org/10.1021/nn202190c

[36] J. Park, S. Park, S. Ryu, S.H. Bhang, J. Kim, J.-K. Yoon, Y.H. Park, S.-P. Cho, S. Lee, B.H. Hong and B.-S. Kim, Grapheneregulated cardiomyogenic differentiation process of mesenchymal stem cells by enhancing the expression of extracellular matrix proteins and cell signaling molecules, Adv. Healthc. Mater., 2014, vol. 3, no. 2, pp. 176-181. https://doi. org/10.1002/adhm.201300177

[37] J. Kazantseva, I. Hussainova, R. Ivanov, T. Neuman and M. Gasik, Hybrid graphene-ceramic nanofibers network for spontaneous neural differentiation of stem cells, Interface Focus, 2018, vol. 8, no. 3, art. 20170037. http://dx.doi.org/10.1098 rsfs.2017.0037
[38] J. Kazantseva, R. Ivanov, M. Gasik, T. Neuman and I. Hussainova, Graphene-Augmented Nanofiber Scaffolds Trigger Gene Expressions Switching of Four Cancer Cell Types, ACS Biomater. Sci. Eng., 2018, vol. 4, no. 5, pp. $1622-$ 1629. https://doi.org/10.1021/acsbiomaterials.8b00228

[39] J. Argüello, V.L. Leidens, H.A. Magosso, R.R. Ramos and Y. Gushikem, Simultaneous voltammetric determination of ascorbic acid, dopamine and uric acid by methylene blue adsorbed on a phosphorylated zirconia-silica composite electrode, Electrochim. Acta, 2008, vol. 54, no. 2 , pp. 560-565. https://doi. org/10.1016/j.electacta.2008.07.021

[40] F. Ye, C. Feng, J. Jiang and S. Han, Simultaneous determination of dopamine, uric acid and nitrite using carboxylated graphene oxide/lanthanum modified electrode, Electrochim. Acta, 2015, vol. 182, no. 10, pp. 935-945. https://doi.org/10.1016/j.electacta.2015.10.001

[41] J. Du, R. Yue, F. Ren, Z. Yao, F. Jiang, P. Yang and Y. Du, Novel graphene flowers modified carbon fibers for simultaneous determination of ascorbic acid, dopamine and uric acid, Biosens. Bioelectron., 2014, vol. 53, pp. 220-224. https://doi.org/10.1016/j.bios.2013.09.064

[42] J.-W. Mo and B. Ogorevc, Simultaneous Measurement of Dopamine and Ascorbate at Their Physiological Levels Using Voltammetric Microprobe Based on Overoxidized Poly (1,2phenylenediamine)-Coated Carbon Fiber, Anal. Chem., 2001, vol. 73, no. 6, pp. 1196-1202. https://doi.org/10.1021/ac0010882

[43] H.L. Zou, B.L., Li, H.Q. Luo and N.B. Li, $A$ novel electrochemical biosensor based on hemin functionalized graphene oxide sheets for simultaneous determination of ascorbic acid, dopamine and uric acid, Sens. Actuators B, 2015, vol. 207 part A, pp. 535-541. https://doi.org/10.1016/j.snb.2014.10.121

[44] W. Zhang, R. Yuan, Y.-Q. Chai, Y. Zhang and S.-H. Chen, A simple strategy based on lanthanum-multiwalled carbon nanotube nanocomposites for simultaneous determination of ascorbic acid, dopamine, uric acid and nitrite, Sens. Actuators B, 2012, vol. 166-167, pp. 601607. https://doi.org/10.1016/j.snb.2012.03.018

[45] Y.J. Yang and W. Li, CTAB functionalized graphene oxide/multiwalled carbon nanotube composite modified electrode for the simultaneous determination of ascorbic acid, dopamine, uric acid and nitrite, Biosens. Bioelectron., 2014, vol. 56, pp. 300-306. https://doi.org/10.1016/j.bios.2014.01.037

[46] M. Taleb, R. Ivanov, S. Bereznev, S.H. Kazemi and I. Hussainova, Graphene-ceramic hybrid nanofibers for ultrasensitive electrochemical determination of ascorbic acid, Microchim. Acta, 2017, vol. 184, pp. 897-905. https://doi.org/10.1007/s00604-017-2085-7 
[47] Z. Hsine, S. Bizid, R. Mlika, H. Sauriat-Dorizon, A.H. Said and H. Korri-Youssoufi, Nanocomposite Based on Poly (para-phenylene)/ Chemical Reduced Graphene Oxide as a Platform for Simultaneous Detection of Ascorbic Acid, Dopamine and Uric Acid, Sensors, 2020, vol. 20, no. 5, art. 1256. https://doi.org/10.3390/s20051256

[48] M. Taleb, R. Ivanov, S. Bereznev, S.H. Kazemi and I. Hussainova, Ultra-sensitive voltammetric simultaneous determination of dopamine, uric acid and ascorbic acid based on a graphenecoated alumina electrode, Microchim. Acta, 2017, vol. 184, pp. 4603-4610. https://doi.org/10.1007/s00604-017-2510-y

[49] F. Alonso, Y. Moglie, G. Radivoy and M. Yus, Multicomponent click synthesis of potentially biologically active triazoles catalysed by copper nanoparticles on activated carbon in water, Heterocycles, 2012, vol. 84, no. 2, pp. 1033-1044. https://doi.org/10.3987/COM-11-S(P)81

[50] S. Immanuel and R. Sivasubramian, Fabrication of two-dimensional chemically reduced graphene oxide nanosheets for the electrochemical determination of epinephrine, Bull. Mater. Sci., 2020, vol. 43, art. 79. https://doi.org/10.1007/s12034-019-2034-7

[51] M. Taleb, R. Ivanov, S. Bereznev, S.H. Kazemi and I. Hussainova, Alumina/graphene/Cu hybrids as highly selective sensor for simultaneous determination of epinephrine, acetaminophen and tryptophan in human urine, J. Electroanal. Chem., 2018, vol. 823, pp. 184-192. https://doi.org/10.1016/j.jelechem.2018.06.013 